\title{
Investigating Garment Drape Behaviour
}

\author{
Reham Sanad $^{\mathrm{a}, *}, \quad$ Tom Cassidy ${ }^{\mathrm{b}}$ \\ ${ }^{a}$ Faculty of Applied Arts, Damietta University, Damietta, Egypt \\ ${ }^{\mathrm{b}}$ School of Design, University of Leeds, UK
}

\begin{abstract}
Drapeability is one of the most important visual properties affecting garment appearance. Even though there are many studies concerned with fabric drape, understanding about the drape behaviour of garments is very limited. This study analyzes the key properties affecting the drape behaviour of garments to provide prediction equations. Results are statistically analyzed. From multiple regression analysis, drape rank scores obtained from subjective analyses are predicted using weight, bending modulus and extensibility measured at $100 \mathrm{gf} / \mathrm{cm}$ with a correlation coefficient of 0.94 . Ranking values obtained from subjective analyses can be more easily predicted using both circularity and wave length minimum. A new equation was derived to predict drape rank score values of garments (correlation coefficient $r=0.97$ ) depending on circularity and wavelength minimum.
\end{abstract}

Keywords: Drape; Fabric; Garment; Prediction; Visual; FAST; Mechanical; Parameters

\section{Introduction}

With the advent of fast fashion it is becoming ever more important that designers and technologist be able to predict garment appearance and this is significantly influenced by drape. This is the manner in which a fabric or garment makes folds under the effect of gravity when only part of it is directly supported.

Measurement of fabric drape objectively has long been the concern of textile researchers. The Fabric Research Laboratories Drapemeter (F.R.L.) described by Chu et al. in 1950 was the first apparatus developed considering drape as a three dimensional property [1]. Later in 1965, Cusick made a great contribution to the measurement of fabric drape objectively [2]. Since then, there has been much further development of drapemeters employed in measuring fabric drape. The standard method for measuring drape is based on Cusick's work. The development of the drapemeter from the early beginning until the latest improvement is comprehensively reviewed by Sanad et al. in 2012 [3].

Drape is a complex property and it is an essential parameter to decide both appearance and handle of fabrics. Textile researchers have been interested in investigating drape because of the

\footnotetext{
${ }^{*}$ Corresponding author.

Email address: rehamsanad@du.edu.eg (Reham Sanad).
} 
attempt to create more successful clothing CAD systems by introducing key fabric properties affecting garment drape.

Drape was found dependent on fabric physical and low stress mechanical properties. Therefore, researchers worked on establishing the relationship between drape and these properties. Theoretical prediction has been employed by researchers to identify key factors which contribute to drapeability.

\section{Literature Review}

Chu et al. in 1960 found that drapeability is dependent on three basic parameters: Young's Modulus E, the cross-sectional moment of inertia (I) and weight (W). These factors play important roles in fibre, yarn, and fabric forms. The effect of these quantities on drapeability was expressed as follows: Drape coefficient $=\mathrm{f}(\mathrm{EI} / \mathrm{W})[4]$.

Cusick in 1965 provided statistical evidence that the fabric drape coefficient is dependent on shear stiffness (A) and bending length (c). Regression equations to describe this relation quantitatively were introduced. The model included a combination of 4 variables $\mathrm{c}, \mathrm{c}^{2}, \mathrm{~A}$ and $\mathrm{A}^{2}$ had the lowest residual value. This means that it was the best one fitted to the data [2].

Hearle in 1969 analyzed the nature of fabric deformation in draping. He stated that bending and shear are the main factors affecting drape. Buckling behaviour was also important in determining the form and magnitude of drape but it is related to bending stiffness. He ignored tensile and compressive deformation as these are not comparable to bending and shear deformation [5].

Morooka and Niwa in 1976 stated that they had found no investigation studying the relation between physical properties, other than bending and shear stiffness, and drape coefficient. Therefore they examined a variety of sixteen physical and mechanical properties of woven fabrics measured on a Kawabata Evaluation System (KES-F) contributing to drapeability. Bending rigidity $B R$ and weight per unit area $W$ were the most determinative parameters to drape coefficient, and better agreement was obtained between experimental results and a regression calculation when these are combined in a single parameter $\sqrt[3]{B R / W}[6]$.

Gaucher et al. found that several physical properties were suggested as contributors to the drape of woven fabrics but literature lacks information concerning physical properties influencing the drape of knitted fabrics. Therefore, they carried out multiple regression analysis to predict warp and weft knitted fabric drape coefficients using physical and mechanical properties. It was observed that using a mechanical property value of different face direction, or average of both resulted in prediction equations with different reliability degrees. The overall mean did not always exist in the best predictive equation. Warp knits and weft knits, however, were dependent on different variables. Stiffness, measured in terms of bending length, thickness, and shear, was the factor influencing the drape of knitted fabrics in general. Stiffness, thickness, and extension were the best predictors for warp knits, whereas stiffness and shear were the best predictors for weft knitted constructions [7].

Collier in 1991 measured the drape coefficient of a group of woven tested fabrics using differentsized pedestal plates ( 3 and 5 inches diameter). Stepwise multiple regression was performed for drape coefficient on fabric mechanical properties. Shear hysteresis and bending resistance measured on a KES-F were found to be more closely associated with fabric drape than were thickness and weight. Descriptive mechanical properties were dependant on pedestal size. Bending modulus 
was a significant variable in the regression equation for drape on the $5^{\prime \prime}$ plate, while thickness and flexural rigidity were significant in determining drape values measured on the 3 " plate. Bending modulus and flexural rigidity, as well as shear hysteresis and thickness, were significant in the model predicting the combined drape values. However, shear hysteresis and bending modulus explained most of the variation, with the other two variables being less important [8].

$\mathrm{Hu}$ and Chan in 1998 investigated the relationship between the fabric drape coefficient from the Cusick drapemeter and mechanical properties tested on a KES-F for woven fabrics. They employed stepwise regression analysis using four different models to find the best basic parameter combinations to predict drape coefficient theoretically. It was known that bending and shear properties are closely related to drape coefficient and their analysis showed that two other parameters, mean deviation of friction coefficient and tensile linearity, were also highly correlated with drape coefficient [9].

Okur and Cihan investigated the possibility of predicting drape coefficients using values obtained from Fabric Assurance by Simple Testing (FAST) which is a system developed to be used in the clothing industry. They performed stepwise regression and found that bending length in the warp direction, bending length in the weft direction and extension in the bias $45^{\circ}$ angle at 5 $\mathrm{gf} / \mathrm{cm}$ measured on a FAST system were useful for the prediction of drape [10].

Uçar et al. found that knowledge about the drape behaviour of seamed fabrics was very limited. Therefore they analyzed the effect of five-thread overlock seams on drape behaviour of heavy weight knit fabrics. From a regression analysis, they obtained the drape coefficients of such fabrics using the drape coefficient value of seamless fabric (DC0) and the number of seams. The DC0 was either measured or calculated by the prediction equation developed by Gaucher et al.'s equation in 1983. Prediction of drape coefficient was improved when including the number of nodes in the equation [11].

Jeddah et al. proposed three regression models for predicting drape of plain and twill weave and for all fabrics using the multiple linear regressions using fabric mechanical properties. Bending and shear stiffness were important predictors for drape coefficient in the three models followed by the thickness. The regression coefficients were similar for each parameter in the three equations, therefore they concluded that the weave type has no effect on the regression models [12].

From this review, it is evident that researchers have become increasingly interested in investigating drape to efficiently simulate fabrics in clothing CAD systems. There has been progress in investigating the key properties affecting drape. However, these key factors vary in different studies. This is because of the range of fabrics tested and the systems used for measuring fabric physical or mechanical properties, or the drape measurement system employed.

Researchers indicated that drape is affected by the way in which a fabric hangs to make folds. There is difference between deformation produced when hanging a curtain, skirt or jacket, etc. The first requirement for a physical study of drape was a suitable experimental method for an objective laboratory study of the problem as the supporting body of the drape system has an impact on drape configuration [5]. It was shown that determining factors of fabric drape deformation were dependant on the supporting disc size [8]. Sanad et al. in 2013 developed an alternative system for measuring garment drape. The supporting body in this system is a mannequin and the sample is a dress. It was indicated that most of the drape parameters measured for the fabric had weak correlations with the relative values from garments. They indicated that measuring apparel drape should be carried out using a garment [13]. 
All studies previously found were concerned with predicting fabric drape rather than garment drape. The present work was undertaken to examine the mechanical and physical properties of fabrics which contribute to the drapeability of a garment.

In addition, discussions have concentrated on the relationship between fabric drape rating in subjective assessment and the DC and the number of nodes. However, it is possible that parameters other than those mentioned and introduced by Sanad et al. [13] could influence garment drape. In this paper, we therefore studied the prediction of garment drape ranking using these drape parameters. We anticipated that this would permit the development of prediction equations, so that the drape of a garment could be calculated from knowledge of one or more of its parameters. Multiple stepwise regression techniques gave a clearer picture for our purposes.

\section{Experimental}

\subsection{Materials}

A range of 12 fabrics including 5 nonwovens (N) of weight ranging between 80 to $170 \mathrm{~g} / \mathrm{m}^{2}$ and 7 conventional (woven W and knitted K) ranging between 105 and $260 \mathrm{~g} / \mathrm{m}^{2}$ was used. These were the fabrics tested by Sanad et al. [13] and Tables 1 to 3 list their specifications.

Table 1: Woven fabrics' physical properties

\begin{tabular}{ccccccccc}
\hline \multirow{2}{*}{ Fabric Code } & \multirow{2}{*}{ Weave } & \multirow{2}{*}{$\begin{array}{c}\text { Weight } \\
\left(\mathrm{g} / \mathrm{m}^{2}\right)\end{array}$} & \multicolumn{2}{c}{ Weave count/inch } & & \multicolumn{2}{c}{ Yarn count (Denier) } \\
& & & Ends & Picks & & & Ends & Picks \\
\hline W1 & Plain & 152 & 97 & 62 & & viscose & 308 & 330 \\
W2 & Plain & 108 & 107 & 60 & & viscose & 120 & 120 \\
W3 & Twill & 158 & 110 & 67 & & Polyester & 180 & 337 \\
W4 & Plain & 105 & 102 & 62 & & viscose & 120 & 120 \\
W5 & Plain & 250 & 65 & 60 & & Cotton & 276 & 298 \\
\hline
\end{tabular}

Table 2: Knitted fabrics' physical properties

\begin{tabular}{cccccccc}
\hline $\begin{array}{c}\text { Fabric } \\
\text { Code }\end{array}$ & Construction & Gauge & $\begin{array}{c}\text { Weight } \\
\left(\mathrm{g} / \mathrm{m}^{2}\right)\end{array}$ & Courses/inch & Wales/inch & Fibre type & $\begin{array}{c}\text { Yarn Count } \\
\text { (Denier) }\end{array}$ \\
\hline K1 & interlock & 28 & 260 & 70 & 40 & viscose & 120 \\
K2 & interlock & 28 & 197 & 70 & 45 & Viscose & 120 \\
\hline
\end{tabular}

\subsection{Mechanical Properties Measurement}

Fabric low stress mechanical properties were measured by Sanad et al. 2013 [13]. This is because high correlation had been previously found between fabric drape and the mechanical properties 
Table 3: Nonwoven fabrics' physical properties

\begin{tabular}{ccc}
\hline Fabric code & Weight $\left(\mathrm{g} / \mathrm{m}^{2}\right)$ & Treatment \\
\hline N1 & 100 & Not softened \\
N2 & 80 & Softened \\
N4 & 100 & Softened \\
N5 & 130 & Softened \\
N6 & 170 & Softened \\
\hline
\end{tabular}

(specially bending and shear rigidity properties). The bending length (BL) was measured in $\mathrm{mm}$ using a heart loop test. Extensibility (E) at 5, 20, $100 \mathrm{gf} / \mathrm{cm}$ was measured using the extension meter in a FAST system. Also, Thickness (T) at and $100 \mathrm{gf} / \mathrm{cm}^{2}$ were measured employing the compression meter in the FAST system. Bending rigidity (BR) in $\mu \mathrm{Nm}$, bending modulus (BM) in $\mathrm{Kg} / \mathrm{cm}^{2}$, formability (FR) in $\mathrm{mm}^{2}$ and Surface thickness (ST) in mm were calculated. The average of the three directions: lengthwise, crosswise and bias was calculated for each fabric.

The standard sample size, for FAST, $5 \times 13 \mathrm{~cm}$ was used in all tests. All tested samples in this study were conditioned in a standard atmosphere: $60 \pm 2 \%$ relative humidity and $20 \pm$ $2{ }^{\circ} \mathrm{C}$.

\subsection{Visual Assessment of Drape}

An A line shift dress pattern (size 12) was used to cut dresses from the 12 fabrics tested in this study. The garments were photo captured from below while suspended on a mannequin. Images taken for garments were assessed visually (Sanad et al. 2013) using a panel of expert judges consisting of 20 individuals. They were asked to order each group of images from the most drapeable (highly deformed shape) sample to the least. The Kendall rank correlation coefficient was calculated for each group. Significant coefficient showed a real agreement among the judges. In this case the average rank was used as the final overall rankings.

\subsection{Measurement of Drape Parameters}

An image analysis technique was employed to measure the drape parameters of the images taken for garments in Sanad et al. 2013. The following drape values were measured (i.e., Perimeter (P), Area (A), Circularity (CIRC), Symmetry (R/L between right and left halves and F/B between front and back, peak number), AM/WH (The ratio of wave amplitude to wave height) (This is the ratio of wave height to wavelength), Fourier $(\mathrm{cm})$ (The area under the frequency (Fourier) plot for the measured shape), F/O (\%) (The ratio between areas under frequency and original curves), $\mathrm{D} / \mathrm{O}(\%)$ (This is the ratio between areas under reconstructed and original curves)). The average (A), maximum (MAX), minimum (MIN) and coefficient of variation (CV) of Wave length (WL) height (WH) and amplitude (WA) were also measured.

These values were measured for each photo. The average of each drape parameter of 5 photos for each sample/image was used to represent the sample. These are listed in Sanad et al.'s study 
in 2013 [13].

\section{Results and Discussion}

\subsection{Prediction of Garment Drapeability Using Low Stress Mechanical Properties}

The means of fabric mechanical properties and garment drape rankings are presented in Table 4 . For drape assessment, a low score refers to high drapeability as the assessors were asked to rank the garments from the highest drapeability to the least (as an example knitted garment K2 has the highest drapeability and W5 has the least drape).

Table 4: Drape rankings of garments, physical and mechanical properties measured

\begin{tabular}{ccccccccccccc}
\hline $\begin{array}{c}\text { Fabric } \\
\text { code }\end{array}$ & $\begin{array}{c}\text { Drape } \\
\text { rank }\end{array}$ & W & T2 & T100 & ST & E5 & E20 & E100 & BL & BR & BM & FR \\
\hline K1 & 2.05 & 260 & 0.64 & 0.58 & 0.06 & 7.61 & 14.46 & 21.12 & 8.78 & 1.73 & 1.08 & 0.81 \\
K2 & 1.35 & 197 & 0.63 & 0.54 & 0.09 & 2.84 & 6.82 & 19.70 & 10.88 & 2.49 & 1.93 & 0.67 \\
W1 & 4.2 & 152 & 0.33 & 0.28 & 0.05 & 3.03 & 6.20 & 10.31 & 14.48 & 4.53 & 25.25 & 0.98 \\
W2 & 3.85 & 108 & 0.25 & 0.21 & 0.04 & 2.00 & 4.35 & 8.55 & 14.44 & 3.19 & 42.11 & 0.51 \\
W3 & 8.65 & 158 & 0.54 & 0.504 & 0.03 & 0.00 & 0.06 & 3.11 & 30.33 & 68.43 & 65.41 & 0.27 \\
W4 & 3.7 & 105 & 0.24 & 0.2 & 0.04 & 2.00 & 4.44 & 8.43 & 17.18 & 5.22 & 79.87 & 0.87 \\
W5 & 10.45 & 250 & 0.59 & 0.35 & 0.24 & 0 & 0.33 & 3.13 & 26.55 & 28.99 & 81.57 & 0.64 \\
N1 & 12 & 100 & 0.36 & 0.3 & 0.05 & 0 & 0.00 & 0.20 & 38.30 & 55.09 & 249.65 & 0.00 \\
N2 & 6.3 & 80 & 0.37 & 0.28 & 0.09 & 0 & 0.44 & 1.68 & 21.50 & 7.80 & 43.46 & 0.23 \\
N4 & 9.05 & 100 & 0.46 & 0.34 & 0.12 & 0 & 0.59 & 2.44 & 22.65 & 11.39 & 35.47 & 0.46 \\
N5 & 9.65 & 130 & 0.56 & 0.46 & 0.10 & 0 & 0.16 & 1.18 & 30.17 & 35.02 & 44.02 & 0.38 \\
N6 & 6.7 & 170 & 0.65 & 0.55 & 0.11 & 0 & 0.14 & 1.25 & 35.20 & 72.74 & 53.50 & 0.70 \\
\hline
\end{tabular}

It is noticed that there is a positive correlation between drape, extensibility and bending properties. There were found to be significant correlations between extensibility properties (i.e. E5, E20 and E100) $(r \geq 0.9, p \leq 0.001)$. Bending properties (BL, BM and FR) were correlated well with each other $(r \geq 0.6, p \leq 0.001)$. However BR correlated well with only with BL $(r=0.89$, $p \leq 0.001)$.

In this study, multiple regression analysis was conducted for modelling and analysing the relation between drape rank scores (dependent variable DV) and fabric mechanical properties (independent variables IV). The regression analysis was performed using SPSS software with the following Criteria: Probability-of- $F$-to-remove an independent variable must be higher than or equal to 0.1 .

Multiple regression analysis produced a model including three fabric properties, i.e. weight (W), extensibility at $100 \mathrm{gf} / \mathrm{cm}$ (E100) and bending modulus (BM). The multiple correlation coefficient $(r)$ was considered a measure of the quality of the prediction of the dependent variable; in this case, drape ranking scores. A value of $r$ equals 0.94 , in this investigation, indicates a good level of prediction. The coefficient of determination $\left(R^{2}\right)$ is the proportion of variance in the dependent 
variable (drape) that can be explained by the independent variables. We can see from $R^{2}$ value of 0.88 that W, E100 and BM explained $88 \%$ of the variability of the drape rank score.

The F-ratio, from the ANOVA tests, shows whether the overall regression model is a good fit for the data. It is shown that the independent variables provided a statistically significant prediction of the dependent variable, $F(3,8)=18.68, p<0.001$ (i.e., the regression model was a good fit to the data).

The coefficients obtained from the regression analysis are listed in Table 5. The general form of the equation to predict drape rankings from weight (W), extensibility at $100 \mathrm{gf} / \mathrm{cm}$ (E100) and bending modulus (BM) was produced using the unstandardized coefficients.

Table 5: Coefficients obtained from the regression analysis applied

\begin{tabular}{|c|c|c|c|c|c|}
\hline \multirow{2}{*}{ Model } & \multicolumn{2}{|c|}{ Unstandardized Coefficients } & \multirow{2}{*}{$\frac{\text { Standardized Coefficients }}{\text { Beta }}$} & \multirow{2}{*}{$\mathrm{t}$} & \multirow{2}{*}{ Sig. } \\
\hline & B & Std. Error & & & \\
\hline (Constant) & 5.286 & 1.445 & & 3.658 & 0.006 \\
\hline $\mathrm{W}$ & 0.020 & 0.009 & 0.345 & 2.312 & 0.050 \\
\hline E100 & -0.423 & 0.081 & -0.872 & -5.241 & 0.001 \\
\hline BM & 0.017 & 0.008 & 0.316 & 2.131 & 0.055 \\
\hline
\end{tabular}

Unstandardized coefficients indicate how much the dependent variable varies with an independent variable when all other independent variables are held constant.

The statistical significance of each of the independent variables was tested. We can see from the "Sig." column that all independent variable coefficients are significantly different from 0 (zero), $p<0.05$.

In this part of the study, a multiple regression was run to predict drape from weight (W), extensibility at $100 \mathrm{gf} / \mathrm{cm}$ (E100) and bending modulus (BM). However, the most important factor was found to be E100. W and BM are less important. These variables give a statistically significant prediction of drape, $F(3,8)=18.68, p<0.001, R^{2}=0.88$. All three variables added significantly to the prediction, $p<0.05$.

With regard to volumetric quantities, i.e., weight and thickness, there has been disagreement among researchers about their role in determining drape. Weight was found a key factor of drape by Chu et al. [4] and Morooko and Niwa [6]. Collier found it less important than bending and shear properties [8]. The interesting finding in this study is that fabric weight (volumetric quantity) was a dominant factor in explaining draping behaviour. The impact of weight in predicting drape supports studies considering fabric as a three dimensional structure (engineering material), rather than as a two-dimensional material.

Another volumetric property, i.e., thickness was found important in describing drape by previous researchers $[7,8]$. However in this study thickness was not found to be amongst the good predictors of garment drape.

There were contradictions in previous studies concerned with the contribution of extensibility in determining drape. Extensibility was used by Gaucher et al. [7] and Okur and Cihan [10] as a predictor of drape. In the present research, extension E100 was included in the best prediction equation for garment drape.

It is evident from Table 5 that the bending modulus BM has an important influence on garment 
drape. This result agrees with Collier 1991 [8] and previous work that indicated that fabric bending modulus was one of the most important factors affecting drape.

Although there are some differences among research studies they all agree that bending properties have effects on the prediction of drape. This study reinforces previous research findings.

\subsection{Investigating Alternative Parameter for Garment Drape}

Several studies were carried out investigating the relationship between subjective rankings of fabric drape. Mostly these studies correlated drape coefficient with a subjective ranking.

Chu et al.'s [4] study provided correlation coefficient between drape ranking of subjective analyses and drape coefficient of 0.788 . Ucar et al. found that rating values obtained from subjective analyses can be more easily predicted by using both the number of nodes and DC\% values rather than DC\% values alone. Thus, they derived an equation to predict rating values with a correlation coefficient of $r=0.86$ [11].

A group of 21 drape descriptors/parameters were introduced by Sanad et al. [13] and it was anticipated that using these drape parameters would improve describing drape. Therefore in this current study the most important parameters could predict subjective ranking of drape were investigated.

In this part of the study, multiple regression analysis was run for determining the relation between subjective drape rank scores (dependent variable DV) and drape parameters (independent variables IV). The regression analysis was performed using SPSS software with the following Criteria: Probability-of- $F$-to-enter less than or equal to 0.05 , Probability-of- $F$-to-remove higher than or equal to 0.1 .

It was found that circularity and wave length minimum (WL MIN) were the best predictors of drape rank scores. Coefficients obtained from the regression analysis are listed in Table 6. The equation of predicting drape rankings from Circularity and WL MIN was produced using the unstandardized coefficients. The standardized coefficients evidently suggest that Circularity is more important in determining drape than WL MIN. However there is no big difference between their contributions to drape. Both Circularity and WLMIN were statistically significantly different from 0 (zero) $p<0.05$.

Table 6: Coefficients obtained from the regression analysis

\begin{tabular}{|c|c|c|c|c|c|}
\hline \multicolumn{6}{|c|}{ Coefficients } \\
\hline \multirow{2}{*}{ Model } & \multicolumn{2}{|c|}{ Unstandardized Coefficients } & \multirow{2}{*}{$\frac{\text { Standardized Coefficients }}{\text { Beta }}$} & \multirow{2}{*}{$\mathrm{t}$} & \multirow{2}{*}{ Sig. } \\
\hline & B & Std. Error & & & \\
\hline (Constant) & -9.721 & 1.627 & & -5.976 & 0.000 \\
\hline Circularity & 27.607 & 4.367 & 0.668 & 6.321 & 0.000 \\
\hline WLMIN & 0.122 & 0.031 & 0.411 & 3.890 & 0.004 \\
\hline
\end{tabular}

The multiple correlation coefficients $R$ was 0.97 showing a high level of predicting drape rank scores using Circularity and WLMIN. The coefficient of determination $\left(R^{2}\right)$ value of 0.93 , indicates that the independent variables explain $93 \%$ of the variability of the dependent variable, drape 
rank score.

The $F$-ratio from the ANOVA showed that the independent variables gave a statistically significant prediction of the dependent variable, $F(2,9)=63.19, p<0.001$ (i.e., the regression model was a good fit of the data).

In this portion of the study, it is shown that the rank scores of garments were predicted using Circularity and Wave length minimum (WL MIN), their corresponding average drape parameters were used. It is evident from this part of the study that using Circularity and WL MIN improved determination of garment drape $r=0.97, p>0.005$. However, Circularity is more important than WL MIN.

\section{Conclusions}

This study was concerned with the key low stress mechanical properties affecting the drape behaviour of garment. The properties measured were: weight, thickness at 2 and $100 \mathrm{gf} / \mathrm{cm}^{2}$, surface thickness, extensibility (E) at 5, 20, $100 \mathrm{gf} / \mathrm{cm}$, bending rigidity (BR) in $\mu \mathrm{Nm}$, bending modulus (BM) in $\mathrm{Kg} / \mathrm{cm}^{2}$, formability (FR) in $\mathrm{mm}^{2}$ and surface thickness (ST) in mm. Garment drape was assessed subjectively using a panel of expert judges to rank garments from the highest to the least drapeability. Multiple regression analysis was performed for average garment drape ranks on the low stress mechanical properties measured. It was found that weight, extensibility measured at $100 \mathrm{gf} / \mathrm{cm}$ and bending modulus were the most determinative parameters for garment drape rankings. The drape rankings were predicted satisfactorily with high accuracy (correlation coefficient of 0.94), and the equation for the drape ranking is presented.

The most important mechanical property explaining variability in drape values was extensibility measured at $100 \mathrm{gf} / \mathrm{cm}$. Fabric physical volumetric quantity (weight) was found to be a characterizing factor of garment drape. This indicates the behaviour of fabric as an engineered structure. The bending modulus was found to be an influential property of garment drape. Both weight and bending modulus were found with similar effect on garment drape.

Previous studies have long been concerned with the prediction of conventional drape parameters (namely drape coefficient and number of nodes). In this study, alternative drape parameters proposed by Sanad et al. in 2012 were investigated in terms of their contribution to determining drape. These parameters were: perimeter, area, circularity, Symmetry, peak number, AM/WH (The ratio of wave amplitude to wave height), WH/WL (This is the ratio of wave height to wavelength), Fourier $\left(\mathrm{cm}^{2}\right)$ (The area under the frequency (Fourier) plot for the measured shape), $\mathrm{F} / \mathrm{O}(\%)$ (The ratio between areas under frequency and original curves), D/O (\%) (This is the ratio between areas under reconstructed and original curves). The average (A), maximum (MAX), minimum (MIN) and coefficient of variation (CV) of wave length (WL), height (WH) and amplitude (WA) were also measured.

Multiple regression analysis was conducted for garment drape ranks on these drape parameters. Alternative drape parameters (i.e., circularity and wave length minimum) were introduced and improved prediction of subjective ranking of garment drape to $r=0.97$ from $r=0.86$ introduced by Ucar et al. in 2004 using drape coefficient and number of nodes as drape predictors. It is shown that circularity is more correlated with drape than wavelength minimum.

Therefore, this research successfully demonstrated that physical and mechanical properties can 
be used to predict the drape rankings of garments. In addition, alternative drape parameters were significantly used to demonstrate garment drape.

\section{References}

[1] C. C. Chu, C. L. Cummings, N. A. Teixeira, Mechanics of elastic performance of textile materials - Part V: A study of the factors affecting the drape of fabrics-the development of a drape meter, Text. Res. J., 20(8), 1950, 539-548

[2] G. E. Cusick, The dependence of fabric drape on bending and shear stifness, J. Text. I. T., 56, 1965, 596-606

[3] R. Sanad, T. Cassidy, V. Cheung, Fabric and Garment Drape Measurement - Part 1, JFBI, 5(4), 2012, 341-358

[4] C. C. Chu, M. M. Platt, W. J. Hamburger, Investigation of the factors affecting the drapeability of fabrics, Text. Res. J., 30(1), 1960, 66-67

[5] J. W. S. Hearle, Structural Mechanics of Fibers, Yarns, and Fabrics, New York: Wiley Interscience, 1969

[6] H. Morooka, M. Niwa, Relation between drape coefficients and mechanical properties of fabrics, J. Text. Mach. Soc. Jpn., 22(3), 1976, 67-73

[7] M. L. Gaucher, M. W. King, B. Johnston, Predicting the drape coefficient of knitted fabrics, Text. Res. J., 53(5), 1983, 297-303

[8] B. J. Collier, Measurement of fabric drape and its relation to fabric mechanical properties and subjective evaluation, Cloth. \& Textiles Res. J., 10(1), 1991, 46-52

[9] J. Hu, Y. F. Chan, Effect of fabric mechanical properties on drape, Text. Res. J., 68(1), 1998, $57-64$

[10] A. Okur, T. Cihan, Prediction of fabric drape coefficients from FAST data, Textile Asia, 33(7), 1993, 28-31

[11] N. Uçar, F. Kalaočlu, D. Bahtiyar, O. E. Blaç, Investigating the drape behavior of seamed knit fabrics with image analysis, Text. Res. J., 74, 2004, 166-171

[12] H. Jedda, A. Ghith, F. Sakli, Prediction of fabric drape using the FAST system, J. Text. I., 98(3), 2007, 219-225

[13] R. Sanad, T. Cassidy, V. Cheung, E. Evans, Fabric and garment drape measurement - Part 2, JFBI, 6(1), 2013, 1-22 